\title{
Soluble Fas and Fas ligand in human tear fluid after photorefractive keratectomy
} Ilpo Tuominen, Minna Vesaluoma, Anna-Maija Teppo, Carola Grönhagen-Riska,
Timo Tervo
Helsinki University Eye Hospital, Helsinki, Finland

I Tuominen

M Vesaluoma

T Tervo

Department of Medicine, Helsinki University Hospital, Helsinki, Finland A-M Teppo

C Grönhagen-Riska

Correspondence to: Ilpo Tuominen, Helsinki University Eye Hospital, Eye Bank, PO Box 220,

FIN-00029 HUCH, Finland

Accepted for publication 2 July 1999

\begin{abstract}
Backgroundlaims-The Fas-Fas ligand system is thought to be involved in stromal cell apoptosis after corneal wounding. The aim was to measure changes in human tear fluid levels of soluble Fas (sFas) and Fas ligand (sFasL) following myopic photorefractive keratectomy (PRK).

Methods-Tear samples of 59 patients were collected preoperatively, and 1 or 2 days after PRK. Tear fluid sFas or sFasL concentrations were determined using sandwich ELISAs. Subsequently, tear flow corrected concentrations (releases) were calculated to compensate for the postoperative tear hypersecretion.

Results-The preoperative tear fluid flows (TFF) were $6.4(1.7) \mu 1 / m i n$ (mean (SEM)) in sFas group $(n=18)$, and $7.5(1.5) \mu 1 / \mathrm{min}$ in sFasL group $(n=39)$. Postoperatively TFFs increased to $37.9(10.9) \mu 1 / \mathrm{min}(\mathrm{p}=$ $0.003)$ and $58.3(7.0) \mu 1 / \mathrm{min}(\mathrm{p}=0.000)$, respectively. The mean preoperative sFas concentration (24.4 (11.6) U/ml) decreased to $9.7(4.1) \mathrm{U} / \mathrm{ml}(\mathrm{p}=0.001)$ postoperatively, and the mean sFasL concentration (299.1 (28.8) $\mathrm{ng} / \mathrm{l})$ to 118.7 (15.9) $\mathrm{ng} / \mathrm{l}(\mathrm{p}=\mathbf{0 . 0 0 0})$. However, the release of both substances increased significantly: sFas from $87.3(29.4) \mathrm{mU} / \mathrm{min}$ to $229.4(82.9) \mathrm{mU} / \mathrm{min}(\mathrm{p}=0.002)$ and sFasL from 1620.6 (226.4) $\mathrm{fg} / \mathrm{min}$ to 4777.1 (596.1) $\mathrm{fg} / \mathrm{min}(\mathrm{p}=0.000)$.

Conclusions-Both sFas and sFasL are normal constituents of human tears. Despite a decrease in concentrations related to reflex tears, the release of $\mathrm{sFas}$ and sFasL increases significantly after excimer laser photorefractive keratectomy, which suggests that they are involved in corneal healing after PRK in humans.

(Br f Ophthalmol 1999;83:1360-1363)
\end{abstract}

Apoptosis, or programmed cell death, was recognised by Kerr and colleagues as a distinctive morphology differing from necrosis. ${ }^{12}$ It later proved to be a basic phenomenon occurring during development, tissue homeostasis, and wound healing in essentially all multicellular organisms. ${ }^{3}$ It has been proposed that apoptosis, initiated by injury of corneal epithelial cells, induces the disappearance of anterior keratocytes. ${ }^{4-7}$ Helena et al demonstrated that this same phenomenon also occurs after photorefractive keratectomy (PRK).$^{8}$ Wilson et al suggested that apoptosis is a primary step in corneal wound healing, possibly affecting the outcome of PRK. ${ }^{4}$ Interleukin 1 (IL-1)- interleukin 1 receptor (IL-1R) complex and FasL-Fas complex are presumed to induce apoptosis in the cornea. ${ }^{4}{ }^{10}$ These systems belong to a cell specific pathway, which is thought to trigger the common apoptotic pathway by a molecule, which is not yet identified in higher organisms. The common pathway consists of ICE-like proteases and products of the following genes-Bax, Bcl-2, and Bcl-XL. ${ }^{9}$

The Fas-Fas ligand system consists of four different factors - soluble Fas and FasL, as well as membrane bound Fas and FasL. The Fas is a $45 \mathrm{kD}$ cell surface protein with a transmembrane domain. It belongs to the nerve growth factor receptor-tumour necrosis factor (TNF) receptor family (type I membrane protein). ${ }^{11-13}$ Molecular cloning and nucleotide sequence analysis have revealed a human Fas messenger RNA variant that encodes soluble Fas molecule lacking the transmembrane domain. ${ }^{14}$

The FasL is a type II membrane protein that belongs to the TNF family. ${ }^{11} 16$ The membrane bound FasL is converted to soluble form by a matrix metalloproteinase-like enzyme. ${ }^{17} 18$ The human soluble FasL is a $26 \mathrm{kD}$ glycoprotein consisting of the extracellular region of FasL. ${ }^{19}{ }^{20}$

In cornea FasL protein is expressed in epithelial and endothelial cells, but FasL mRNA is detected in all three cell types. ${ }^{9}$ On the other hand, the soluble form of FasL protein is expressed in wounded ex vivo human epithelium. ${ }^{10}$ IL- $1 \alpha$ induces expression of the transmembrane form of FasL in cultured fibroblasts. ${ }^{10}$ However, both the Fas protein and the mRNA encoding it are detectable in all three cell types of cornea-that is, epithelial cells, keratocytes, and endothelial cells. ${ }^{9} \mathrm{Wil}-$ son et al have also demonstrated that sFas mRNAs are expressed in all corneal cell types. ${ }^{10}$ Binding of FasL, sFasL, or agonistic anti-Fas antibodies to Fas induces apoptosis. ${ }^{19}{ }^{20}$ However, extrinsic sFas prevents cells from undergoing apoptosis by inhibiting the binding of FasL or sFasL to Fas on the cell membrane. ${ }^{1421}$

It has been hypothesised that $\mathrm{sFasL}$ released from the damaged epithelial cells would induce apoptosis by interacting with its receptor Fas on keratocytes. ${ }^{9}{ }^{10}$ Recently, both LASIK and transepithelial PRK were shown to induce less stromal keratocyte apoptosis than PRK performed after surgical epithelial scraping. ${ }^{8}$

Our aim was to study whether sFas and sFasL are normally present in human tears, and whether their concentrations or releases change during the initial healing of PRK wounds. 


\section{Materials and methods \\ PATIENTS}

The present study was performed according to the Declaration of Helsinki, and was approved by the ethics review committee of Helsinki University Eye Hospital. Informed consent was obtained from each patient. Altogether, 59 patients who underwent PRK were included in the study. There were two groups. In sFas group there were 18 patients (seven females and 11 males). The mean age (SD) was 32.0 (9.4) years (range 18-49 years). Tear fluid was collected preoperatively $(n=18)$ and postoperatively on day $2(n=18)$. In the sFasL group there were 41 patients (29 females and 12 males). The mean age in this group was 31.9 (8.4) years (21-58 years). Tear fluid was collected preoperatively $(\mathrm{n}=39)$ and postoperatively on day 1 or $2(n=31)$. Before operation the patients were examined carefully and showed no signs of ocular inflammation, allergy, or other ocular diseases. The patients were advised not to wear their contact lenses 2 weeks before operation.

\section{TEAR FLUID SAMPLES}

Tear fluid samples were collected with scaled 5 or $25 \mu \mathrm{l}$ fire polished microcapillaries as previously described by van Setten et al. ${ }^{22}$ Special attention was paid not to irritate the cornea or conjunctiva. The collection time (minutes) and the volume $(\mu \mathrm{l})$ were recorded. The tear fluid flow, TFF $(\mu \mathrm{l} / \mathrm{min})$, was used as an estimate of the tear secretion rate. The flow corrected concentration - that is, release, was calculated ( $\mathrm{mU} / \mathrm{min}$ for $\mathrm{sFas}$ and $\mathrm{fg} / \mathrm{min}$ for $\mathrm{sFasL}$ ) to compensate for the dilution effect caused by hypersecretion of tears after PRK. Vesaluoma et al have earlier discussed the benefits and drawbacks of this technique. ${ }^{23}$ Samples were kept frozen in $-70^{\circ} \mathrm{C}$ until determination.

POSTOPERATIVE MEDICATION AND EYE PATCHING Each eye was pressure patched for 2-3 days following PRK. In the morning of the first and/or second postoperative day the patch was removed and the lids were gently cleaned with a paper wipe. After waiting for about 30 seconds the tear fluid sample was collected. Then the chloramphenicol ointment (Oftan Chlora; Leiras, Tampere, Finland) was applied and the eye was repatched. The chloramphenicol ointment was used twice a day for 4 days postoperatively. The pain medication included oral diclofenac sodium 25 mg (Voltaren; CibaGeigy, Basle, Switzerland). It was given 30 minutes before the operation and two to three times a day for the first days after PRK and oral diazepam 5-10 mg (Diapam; Orion, Espoo, Finland) for the first two postoperative nights.

SOLUBLE FAS AND FASL ELISA

Soluble human Fas was determined using enzyme linked immunoassay (SAPO-1/Fas ELISA, Zymed Laboratories, Inc, CA, USA). sFas present in tears diluted 5-20-fold was allowed to bind to monoclonal anti-Fas antibodies, which were absorbed onto the wells of the microtitre plate. The captured Fas was then allowed to react with biotin conjugated anti-
Fas following incubation with streptavidin peroxidase. The enzyme activity, which was in proportion to the amount of $\mathrm{sFas}$ in the samples, was then measured by adding a specific substrate, and by measuring the optical density of the coloured product at $450 \mathrm{~nm}$.

Soluble Fas ligand, CD 95 ligand, or APO-1 ligand concentration was determined using soluble Fas ligand ELISA kit (Medical and Biological Laboratories Co, Ltd, Naka-ku Nagoya, Japan). Tear samples were diluted $2-15$-fold. The kit used anti-Fas ligand monoclonal antibodies against two different epitopes. Samples to be measured or standards were incubated in the wells coated with anti-Fas ligand monoclonal antibody, $4 \mathrm{H} 9$. After washing, a peroxidase conjugated monoclonal antibody, 4A5, was added in the microwell and incubated. After another washing, peroxidase substrate and chromogen were mixed and incubated for an additional period of time. An acid solution was added to terminate the enzyme reaction and to stabilise the developed colour. The optical density was measured at $450 \mathrm{~nm}$ using a microplate reader. The concentration of $\mathrm{sFas}$ ligand was calibrated from a dose-response curve based on reference standards. The concentration value read from the standard curve was then multiplied by the dilution factor.

\section{PHOTOREFRACTIVE KERATECTOMY}

The epithelium was surgically abraded (diameter $6.5-7.0 \mathrm{~mm}$ ) using a Beaver eye blade (Beckton Dickinson, Franklin Lakes, NJ, USA). Six $\mathrm{mm}$ wide PRKs were performed using a VisX 20/20 excimer laser (VisX Co, Sunnyvale CA, USA) for the sFasL group. The mean ablation depth in this group was $60.9 \mu \mathrm{m}$ (SD 21.1; range 16-104 $\mu \mathrm{m}$ ). Six $\mathrm{mm}$ wide PRKs were performed using a Nidek EC 5000 excimer laser (Nidek, Gamagoni, Aichi, Japan) for the sFas group. In the sFas group the mean ablation depth was $65.7 \mu \mathrm{m}$ (SD 32.2; range $17-113 \mu \mathrm{m})$.

\section{STATISTICAL ANALYSIS}

Wilcoxon's signed rank test (the two group paired test) was used to obtain the probability (p) values to assess the significance of changes in tear fluid flow, concentration and release of various substances in tears during healing of the PRK wound. The factors measured at day 1 or 2 were compared with the preoperative level. Results were presented as means, standard errors of mean, and ranges. $\mathrm{p}$ Values less than 0.05 were considered significant. All concentrations below the detection limits were expressed as the values of the detection limits and were included in the statistical analyses.

\section{Results}

SOLUBLE FAS GROUP

The TFF in the collection capillary was 6.4 (1.7) $\mu \mathrm{l} / \mathrm{min}$ (mean (SEM); range $0.5-32.8$ $\mu \mathrm{l} / \mathrm{min}$ ) preoperatively, and 37.9 (10.9) $\mu \mathrm{l} / \mathrm{min}$ $(3.8-192.3 \mu \mathrm{l} / \mathrm{min})$ postoperatively $(\mathrm{p}=$ 0.003). All preoperative and postoperative samples contained sFas. The sFas concentration was $24.4(11.6) \mathrm{U} / \mathrm{ml}(2.0-200.0 \mathrm{U} / \mathrm{ml})$ 


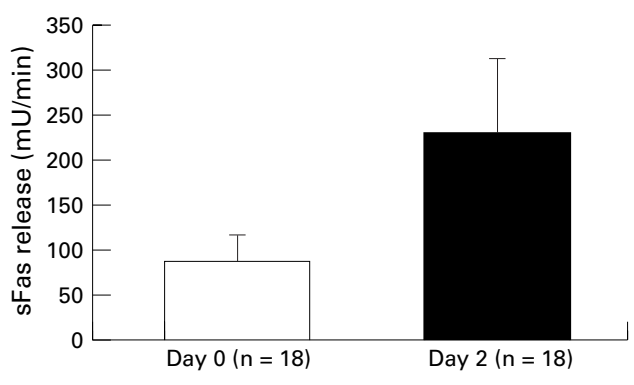

Figure 1 Mean preoperative (day 0 ) and postoperative (day 2) sFas release in human tear fluid ( $\mathrm{mU} / \mathrm{min}$ ). Standard errors of mean (SEM) are presented as error bars.

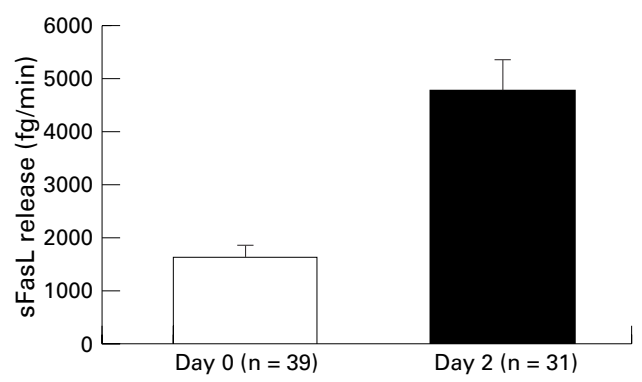

Figure 2 Mean preoperative (day 0) and postoperative (day 2) sFasL release in human tear fluid ( $f g / \mathrm{min})$. Standard errors of mean (SEM) are presented as error bars.

preoperatively, and decreased postoperatively to $9.7(4.1) \mathrm{U} / \mathrm{ml}(1.0-75.0 \mathrm{U} / \mathrm{ml} ; \mathrm{p}=0.001)$. The preoperative sFas release was 87.3 (29.4) $\mathrm{mU} / \mathrm{min}$ (1.1-474.6 $\mathrm{mU} / \mathrm{min})$, and increased postoperatively to $229.4(82.9) \mathrm{mU} / \mathrm{min}(9.4$ $1222.8 \mathrm{mU} / \mathrm{min} ; \mathrm{p}=0.002$ ) (Fig 1 ). The interindividual variations in the sFas concentrations and releases were high. The sFas release increased in 15 out of 18 samples (mean increase $496 \%, 32-3235 \%$ ). On the other hand, the release decreased in three out of 18 samples, and the mean decrease in this group was $31.5 \%$.

\section{SOLUBLE FAS LIGAND GROUP}

In this group the TFF was 7.5 (1.5) $\mu \mathrm{l} / \mathrm{min}$ $(1.0-38.2 \mu \mathrm{l} / \mathrm{min})$ preoperatively, and 58.3 (7.0) $\mu \mathrm{l} / \mathrm{min}(6.7-135.1 \mu \mathrm{l} / \mathrm{min})$ postoperatively $(p=0.000)$. All but one preoperative and all postoperative samples contained sFasL. The sFasL concentration was 299.1 (28.8) ng/1 (73.7-880.0 ng/l) preoperatively, and decreased postoperatively to 118.7 (15.9) ng/l (10.0-420.0 ng/l; p = 0.000). However, the preoperative sFasL release was 1620.6 (226.4) $\mathrm{fg} / \mathrm{min}$ (112.0-5714.0 fg/min), and increased postoperatively to $4777.1 \quad(596.1) \mathrm{fg} / \mathrm{min}$ (750.0-15672.0 fg/min; $\mathrm{p}=0.000$ ) (Fig 2). The interindividual variations in the sFasL concentrations and releases were substantial. The release increased in 24 out of 30 samples, and the mean increase was $881 \%$ (35$7936 \%$ ). The release decreased in six out of 30 samples (mean decrease $28 \%, 10.2-67.1 \%$ ).

\section{Discussion}

The results of the present study show that sFas and sFasL are normal constituents of human tear fluid. Their releases increase significantly after excimer laser PRK.
Experimental studies have shown that apoptosis is involved in homeostasis and turnover of corneal epithelium. ${ }^{24}$ Shed epithelial cells may thus offer one source for sFas and sFasL in normal tear fluid.

According to Stuart et al FasL plays an important role in corneal allograft survival after transplantation. ${ }^{25}$ FasL in cornea would thus contribute to corneal immune privilege by inducing apoptosis in Fas containing lymphoid cells and limiting inflammatory response. ${ }^{25}$ Wilson et al have demonstrated that herpes simplex virus 1 (HSV-1) primary infection in cornea causes apoptotic death of anterior stromal keratocytes. ${ }^{26}$ The hypothesised explanation was that programmed cell death of anterior keratocytes prevented viral extension to the inner corneal layers.

Other potential modulators of apoptosis, such as TNF- $\alpha$, IL- $1 \alpha$, and IL- $1 \beta$, have also been determined in tear fluid earlier. ${ }^{23}{ }^{27}$ Sakata et al have investigated the effect of closed eye on polymorphonuclear leucocytes (PMNs) in tear fluid. ${ }^{28}$ Their results showed increased recruitment, activation, and degranulation of PMNs because of closed eye environment. What the effect of postoperative pressure patching is on sFas and sFasL expression and possible leucocyte invasion in tear fluid is not yet known.

There are plenty of potential sources for these cytokines found in tears: corneal, conjunctival or inflammatory cells, main and accessory lacrimal glands, or leakage from the conjunctival vessels. ${ }^{29}$ Brignole et al have found Fas on normal conjunctival epithelial cells. ${ }^{30}$ However, FasL is not as widely expressed on conjunctival as on corneal epithelium. Whether $\mathrm{sFas}$ or $\mathrm{sFasL}$ is released in tear fluid from the lacrimal glands is not yet known.

The presence of matrix metalloproteinases (MMPs) in cornea has recently been verified, and they have been suggested to be involved in corneal wound healing. ${ }^{31}$ MMPs may also have a role in converting membrane bound FasL to soluble form in tear fluid or cornea. ${ }^{17} 18$

What the possible role and significance of $\mathrm{sFas}$ and $\mathrm{sFasL}$ in normal human tear fluid is, is not yet known. Their increased release following PRK suggests influence on wound healing. Wilson et al suggested that the epithelial injury caused during excimer laser PRK treatment would result in leakage of FasL from the epithelium. ${ }^{9}{ }^{10}$ Soluble FasL in human tear fluid could be one factor triggering apoptosis by interacting with membrane bound Fas receptors on the stromal keratocytes, ${ }^{9} 10$ while anterior stromal keratocytes are in direct contact with tear fluid as long as an epithelial defect can be observed. On the other hand, the fact that the release of sFas increases after PRK makes the situation somewhat more complex, while $\mathrm{sFas}$ is known to inhibit apoptosis by interacting with soluble or membrane bound FasL. ${ }^{1421}$ One could speculate the existence of an equilibrium between these molecules, which would result in modulation of cellular events during wound healing. On the basis of current information we hypothesise that increased release of sFas and sFasL in human tear fluid is 
an indicator of outgoing wound healing process and may even modulate the outcome of excimer laser PRK. An alternative possibility is that the presence of sFas and sFasL in tears, showing substantial interindividual variation, is resulting from normal cell turnover, and that the increases of these substances in tear fluid after PRK just reflects increased cell death.

Part of this study was presented as a poster in ARVO 1998, Fort Lauderdale, Florida.

Financial support: Finnish Eye Foundation, Finland, Finnish Tissue and Eye Bank Foundation, Finland, Finnish Medical Council, Finland, Helsinki University Central Hospital, Finland.

1 Kerr JF. Shrinkage necrosis: a distinct mode of cellular death. F Pathol 1971;105:13-20.

2 Kerr JF, Wyllie AH, Currie AR. Apoptosis: a basic biological phenomenon with wide-ranging implications in tissue kinetics. Br f Cancer 1972;26:239-57.

3 Cohen JJ. Apoptosis: physiologic cell death. F Lab Clin Med 1994;124:761-5.

4 Wilson SE, He YG, Weng J, et al. Epithelial injury induces keratocyte apoptosis: hypothesized role for the keratocyte apoptosis: hypothesized role for the
interleukin-1 system in the modulation of corneal tissue interleukin-1 system in the modulation of corneal tissue
organization and wound healing. Exp Eye Res 1996;62: organiza $325-38$.

5 Nakayasu K. Stromal changes following removal of epithelium in rat cornea. $\mathcal{F p n} \mathcal{F}$ Ophthalmol 1988;32:11325.

6 Crosson CE. Cellular changes following epithelial abrasion. In: Beuerman RW, Crosson CE, Kaufman HE, eds. Healing processes in the cornea. Houston: Gulf Publishing;1989:314.

7 Campos M, Szerenyi K, Lee M, et al. Keratocyte loss after corneal deepithelialization in primates and rabbits. Arch Ophthalmol 1994;112:254-60.

8 Helena MC, Baerveldt F, Kim WJ, et al. Keratocyte apoptosis after corneal surgery. Invest Ophthalmol Vis Sci 1998;39: 276-83.

9 Wilson SE, Li O, Weng J, et al. The Fas-Fas ligand system and other modulators of apoptosis in the cornea. Invest and other modulators of apoptosis
Ophthalmol Vis Sci 1996;37:1582-92.

10 Mohan RR, Liang Q, Kim WJ, et al. Apoptosis in the cornea: further characterization of Fas/Fas ligand system. Exp Eye further characterization

11 Nagata S, Golstein P. The Fas death factor. Science 1995;267:1449-56.

12 Itoh N, Yonehara S, Ishii A, et al. The polypeptide encoded by the cDNA for human cell surface antigen Fas can mediate apoptosis. Cell 1991;66:233-43.

13 Yonehara S, Ishii A, Yonehara M. A cell-killing monoclonal antibody (anti-Fas) to a cell surface antigen $\mathrm{CO}^{-}$ downregulated with the receptor of tumour necrosis factor. f Exp Med 1989;169:1747-56.

14 Cheng J, Zhou T, Liu C, et al. Protection from Fas-mediated apoptosis by a soluble form of the Fas molecule. Science 1994;263:1759-62.

15 Gruss HJ, Dower SK. Tumour necrosis factor ligand superfamily: involvement in the pathology of malignant lymphomas. Blood 1995;85:3378-404.

16 Suda T, Takahashi T, Golstein P, et al. Molecular cloning and expression of the Fas ligand, a novel member of the tumour necrosis factor family. Cell 1993;75:1169-78.

17 Kayagaki N, Kawasaki A, Ebata T, et al. Metalloproteinasemediated release of human Fas ligand. $f$ Exp Med 1995;182:1777-83.

18 Tanaka M, Suda T, Takahashi $\mathrm{T}$, et al. Expression of the functional soluble form of human fas ligand in activated lymphocytes. EMBO f 1995;14:1129-35.

19 Suda T, Okazaki T, Naito Y, et al. Expression of the Fas ligand in cells of T cell lineage. F Immunol 1995;154:3806-13.

20 Watanabe-Fukunaga R, Brannan CI, Itoh N, et al. The cDNA structure, expression, and chromosomal assignment of the mouse Fas antigen. F Immunol 1992;148:1274-9.

21 Tanaka M, Suda T, Haze K, et al. Fas ligand in human serum. Nat Med 1996;2:317-22.

22 Van Setten GB, Viinikka L, Tervo T, et al. Epidermal growth factor is a constant component of normal human tear fluid. Graefes Arch Clin Exp Ophthalmol 1989;227:184-7.

23 Vesaluoma M, Teppo AM, Gronhagen-Riska C, et al. Increased release of tumour necrosis factor- $\alpha$ in human tear fluid after excimer laser induced corneal wound. $B r f$ Ophthalmol 1997;81:145-9.

24 Ren H, Wilson G. Apoptosis in the corneal epithelium. Invest Ophthalmol Vis Sci 1996;37:1017-25.

25 Stuart PM, Griffith TS, Usui N, et al. CD95 ligand (FasL)induced apoptosis is necessary for corneal allograft survival. F Clin Invest 1997;99:396-402.

26 Wilson SE, Pedroza L, Beuerman R, et al. Herpes simplex virus type-1 infection of corneal epithelial cells induces apoptosis of the underlying keratocytes. Exp Eye Res 1997; 64:775-9.

27 Nakamura Y, Sotozono C, Kinoshita S. Inflammatory cytokines in normal human tears. Curr Eye Res 1998;17: 673-6.

28 Sakata M, Sack RA, Sathe S, et al. Polymorphonuclear leukocyte cells and elastase in tears. Curr Eye Res 1997,16: 810-19.

29 Vesaluoma MH, Tervo TT. Tenascin and cytokines in tear fluid after photorefractive keratectomy. I Refract Surg 1998;14:447-54.

30 Brignole F, De Saint-Jean M, Goldschild M, et al.Expression of Fas-Fas ligand antigens and apoptotic marker APO2.7 by the human conjunctival epithelium. Positive correlation with class II HLA DR expression in inflammatory ocular surface disorders. Exp Eye Res 1998;67:687-97.

31 Azar DT, Hahn TW, Jain S, et al. Matrix metalloproteinases are expressed during wound healing after excimer laser keratectomy. Cornea 1996;15:18-24. 